\title{
Recent advances in solid state NMR characterization of zeolites
}

\author{
Shenhui Li, Lei Zhou, Anmin Zheng, Feng Deng* \\ National Center for Magnetic Resonance in Wuhan, State Key Laboratory of Magnetic Resonance and Atomic and Molecular Physics, Wuhan Institute of \\ Physics and Mathematics, Chinese Academy of Sciences, Wuhan 430071, Hubei, China
}

\section{A R T I C L E I N F}

Article history:

Received 7 November 2014

Accepted 11 December 2014

Published 20 June 2015

\section{Keywords:}

Solid state NMR

Zeolite

Structure determination

Acid site

Host-guest interaction

\begin{abstract}
A B S T R A C T
Zeolites are widely used as ion exchangers, adsorbents and catalysts in the chemical and petrochemical industries because of their pore structure and acidity. Solid state NMR is a powerful tool for the characterization of the topological structure, active sites (acid sites) and host-guest interaction in zeolites. Recent advances in the solid state NMR characterization of zeolites are briefly reviewed.
\end{abstract}

(C) 2015, Dalian Institute of Chemical Physics, Chinese Academy of Sciences. Published by Elsevier B.V. All rights reserved.

\section{Introduction}

Zeolites are one of the most important class of porous materials and are widely used as catalysts, adsorbents, and ion exchangers. The wide application of zeolites in the chemical and petrochemical industries is due to their unique pore topologies and tunable acid-base properties [1]. The catalytic performance of a zeolite in a heterogeneously catalyzed process is strongly dependent on the acidic property and pore structure. All the fundamental issues can be addressed on the basis of the characterization of the zeolite, investigation of the acidic property of the zeolite and elucidation of the catalytic reaction by various spectroscopic techniques.

Solid state NMR spectroscopy is a well-established spectroscopic tool for the structural characterization and kinetics study of solid materials at the atomic scale [2]. The chemical composition of a solid material can be elucidated from the chemical shifts. The nuclear environment in a solid can be investigated using 2D homo- and hetero-nuclear correlation ex- periments, which are based on coherence transfer by either $J$ coupling or dipolar coupling. The $J$ - and dipolar interactions give information about through-bond connectivity and through-space proximity. Meanwhile, homo- and hetero-nuclear dipolar interactions can provide an accurate measurement of the inter-nuclear distances.

With the development of solid state NMR methodologies and high field spectrometers, solid state NMR is an important tool to use to address various fundamental scientific issues in zeolitic systems. Various state-of-the-art solid state NMR techniques facilitate the applications of solid state NMR techniques for the determination of the topological structure of zeolites, characterization of the active sites in zeolites, observation of the detailed host-guest interactions inside zeolites and elucidation of the crystallization process and catalytic reaction mechanism of zeolites. Here, recent progress in solid state NMR characterization of the topological structures, active sites (acid sites) and host-guest interactions are briefly reviewed, but progress on in situ solid state NMR characterization of catalytic

\footnotetext{
* Corresponding author. Tel: +86-27-87198820; Fax: +86-27-87199291; E-mail: dengf@wipm.ac.cn This work was supported by the National Natural Science Foundation of China $(21210005,21221064$ and 21373265). DOI: 10.1016/S1872-2067(14)60290-4 | http://www.sciencedirect.com/science/journal/18722067 | Chin. J. Catal., Vol. 36, No. 6, June 2015
} 
reactions in zeolites is not included.

\section{Solid state NMR determination of zeolite topological structure}

Determination of a zeolite structure usually relies on the $\mathrm{X}$-ray diffraction (XRD) approach. However, it is difficult to use powder XRD to solve the structure of a zeolite that cannot form single crystals. The intra-molecular distances are of great significance in solving the three-dimensional structure of a zeolite. To establish the ${ }^{29} \mathrm{Si}-{ }^{29} \mathrm{Si}$ correlation and determine the long range $\mathrm{Si}-\mathrm{Si}$ distances in a zeolite framework, Levitt et al. [3-4] introduced a new type of ${ }^{29} \mathrm{Si}$ magic angle spinning (MAS) NMR experiment by incorporating the homo-nuclear dipolar recoupling sequence SR26411. In the two-dimensional (2D) ${ }^{29} \mathrm{Si}$ double-quantum (DQ) MAS NMR spectrum of zeolite Sigma-2 shown in Fig. 1(a), the spatial proximity of the different ${ }^{29} \mathrm{Si}$ sites was manifested. The presence of a signal in the ${ }^{29} \mathrm{Si} \mathrm{DQ}$ MAS spectrum indicated that two silicon sites were in close proximity as the DQ coherence observed was strongly dependent on the internuclear distance. The peaks that occur along the diagonal $(\omega, 2 \omega)$ were autocorrelation peaks resulting from the dipolar interaction of silicon sites with the same chemical shift, while pairs of off-diagonal peaks at $\left(\omega_{a}, \omega_{a}+\omega_{b}\right)$ and $\left(\omega_{\mathrm{b}}, \omega_{\mathrm{a}}+\omega_{\mathrm{b}}\right)$ corresponded to correlations between two silicon sites with different chemical shifts. The autocorrelation peaks for the 1-1 pair were clearly observed in the dipole-based ${ }^{29}$ Si DQ MAS spectrum (Fig. 1(a)), while these were absent in the J-based ${ }^{29} \mathrm{Si}$ DQ MAS spectrum (Fig. 1(b)). This revealed that a direct bond connectivity for $\mathrm{Si}_{1}-\mathrm{Si}_{1}$ was likely not present, while there was long range spatial proximity between $\mathrm{Si}_{1}-\mathrm{Si}_{1}$ pairs. The long range ${ }^{29} \mathrm{Si}-{ }^{29} \mathrm{Si}$ distances of various $\mathrm{Si}-\mathrm{Si}$ pairs can be extracted from the ${ }^{29} \mathrm{Si} \mathrm{DQ}$ curves as a function of the homo-nuclear recoupling time [3,4]. In addition, as shown in Fig. $1(\mathrm{~b})$, the two-bond ${ }^{29} \mathrm{Si}-{ }^{29} \mathrm{Si}$ connectivity in Sigma-2 can also be obtained from a 2D J coupling-based refocused INADEQUATE experiment [4]. Both the spatial proximity and bond connection information can be obtained from the ${ }^{29} \mathrm{Si}-{ }^{29} \mathrm{Si}$ correlations from the dipolar and $J$ coupling interac-

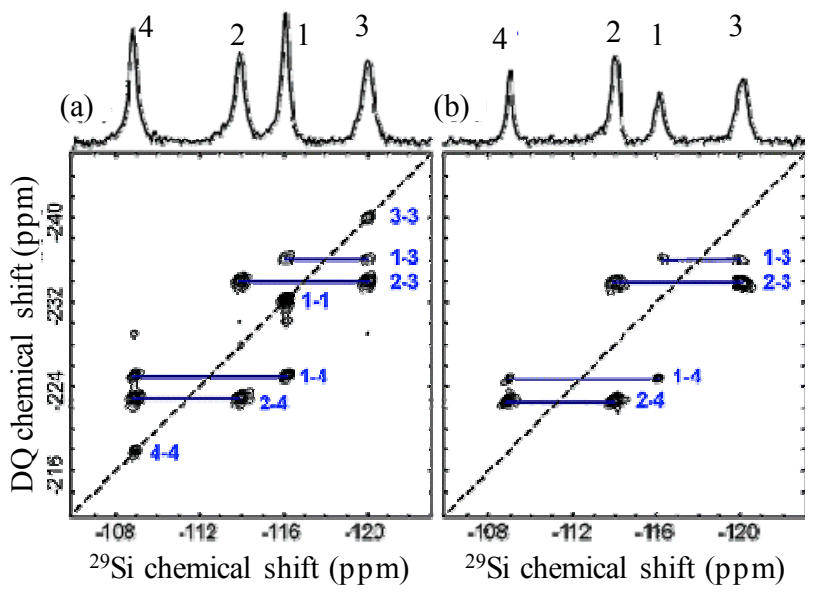

Fig. 1. 2D ${ }^{29} \mathrm{Si}$ DQ correlation spectra of Sigma-2 acquired with (a) SR2 $64_{4}{ }^{11}$ dipolar recoupling sequence and (b) J coupling-based refocused INADEQUATE [4]. tions.

Short and long range ${ }^{29} \mathrm{Si}-{ }^{29} \mathrm{Si}$ distances are of great importance in determining the 3D structure of zeolites. With the unit cell parameters and space group from powder XRD, the 3D topological structure of purely siliceous zeolites can be accurately determined from the long range and short range ${ }^{29} \mathrm{Si}-{ }^{29} \mathrm{Si}$ distances obtained from the 2D ${ }^{29}$ Si MAS NMR experiments [3]. This method opens up a new high resolution structure determination of zeolites by solid state NMR spectroscopy.

The anisotropy of the ${ }^{29} \mathrm{Si}$ shielding interactions arising from the $\mathrm{Si}$ environments of different tetrahedral geometries strongly depend on the structure of the zeolite. The structure of the zeolite can be extracted by the incorporation of the ${ }^{29} \mathrm{Si}$ chemical shift anisotropy (CSA). Fig. 2 shows the CSA pattern of the 7 distinct Si sites of ZSM-12 zeolite using a robust 2D CSA recoupling pulse sequence [5]. After line shape fitting of the CSA pattern, the principal components of the ${ }^{29} \mathrm{Si}$ CSA tensors of the 7 distinct $\mathrm{Si}$ sites were quantitatively determined. The best fit values of the isotropic chemical shift $\left(\delta_{\text {iso }}\right)$ and asymmetry parameter $(\eta)$ for each distinct $\mathrm{Si}$ sites can then be calculated. The ${ }^{29} \mathrm{Si} \mathrm{CSA}$ is very sensitive to the local structure around each Si atom. Thus, the measurement and $a b$ initio calculation of the ${ }^{29} \mathrm{Si}$ shielding tensors can be incorporated into the NMR crystallography of the zeolite to refine the structure of the zeolite [5]. The strategy from ${ }^{29} \mathrm{Si}$ CSA is helpful in the structural determination of a zeolite in which the diffraction techniques provided limited information due to the structural complexity of the zeolite.

Theoretical calculations can also be applied to determine the topological framework structure of the zeolite on the basis of ${ }^{29} \mathrm{Si}$ NMR chemical shifts. Hammond et al. [6] demonstrated that the framework structure of nitrogen-doped zeolites can be elucidated from the ${ }^{29} \mathrm{Si}$ MAS NMR spectra in conjunction with quantum chemical calculations. In addition, the zeolite structure can also be resolved from the ${ }^{29} \mathrm{Si}$ NMR chemical shifts and scalar coupling in conjunction with quantum chemical calcula-

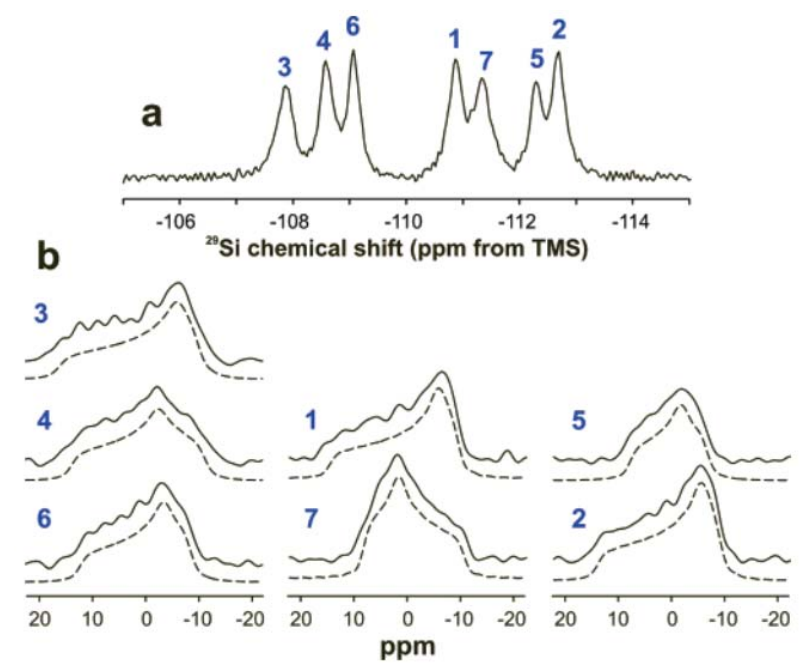

Fig. 2. (a) $1 \mathrm{D}{ }^{29} \mathrm{Si}$ MAS NMR spectrum of ZSM-12 zeolite. (b) Experimental (solid lines) and best fit simulated (dashed lines) quasi-static CSA recoupled line shapes for the indicated Si sites from the 2D spectrum of ZSM-12 [5]. 
tions. Cadars and coworkers [7] proposed that the ${ }^{29} \mathrm{Si} J$ coupling interaction can be used as a sensitive probe for the local structure of the zeolite framework and offers new opportunities for solving complicated zeolite structures.

\section{Solid state NMR studies of the acid sites in zeolites}

The acidity of the zeolite dictates its catalytic performance in hydrocarbon reactions. Thus, an investigation of the acid sites is crucial for the design, modification and application of zeolites. The most important features in the acidity characterization lie in the precise determination of the acid type (Brönsted Brönsted or Lewis), strength, concentration, and distribution (or location) of the acid sites [8,9].

170 MAS NMR was proposed by Peng et al. [10] for investigating the Brönsted acid site in a zeolite. An 170 isotopically-enriched zeolite was prepared by the calcination of the zeolite in an ${ }^{17} \mathrm{O}$-enriched oxygen atmosphere to incorporate ${ }^{17} \mathrm{O}$ atoms into the zeolite framework. To detect the 170 site in the Brönsted acid sites, several solid state NMR techniques including ${ }^{1} \mathrm{H}-17 \mathrm{O}$ REDOR and ${ }^{1} \mathrm{H}-17 \mathrm{O}$ HETCOR were conducted [10-12].

Fig. 3 shows the ${ }^{17} \mathrm{O}\left\{{ }^{1} \mathrm{H}\right\}$ REDOR NMR spectra of ${ }^{17} \mathrm{O}$-enriched HY zeolite [10]. The intensity of the shoulder at $\delta$ $=-24$ decreased significantly in the double resonance experiment, while the intensity of the broad peak at $\delta=21$ remained almost unchanged. According to the double resonance experiment, the shoulder signal at $\delta=-24$ can be associated with the oxygen site in the Brönsted acid site ( $\mathrm{Si}-\mathrm{OH}-\mathrm{Al}$ ), while the broad peak at $\delta=21$ was assigned to the framework oxygen site in the Si-O-Si linkages [10]. A ${ }^{1} \mathrm{H}^{17} \mathrm{O}$ CP-REDOR NMR experiment was further applied to determine the $\mathrm{O}-\mathrm{H}$ distance in zeolite HY. The O-H distance was measured to be 0.098-0.101 $\mathrm{nm}$ [11]. The ${ }^{17} \mathrm{O}$ isotropic chemical shifts $(\delta)$ and quadrupolar coupling parameters for the oxygen sites in Brönsted acid site were extracted from the ${ }^{1} \mathrm{H}-170$ CP-HETCOR NMR spectra [11]. Brönsted acid sites in other zeolites, including H-ZSM-5 and $\mathrm{H}$-mordenite, were also investigated by ${ }^{170}$ MAS NMR spec-

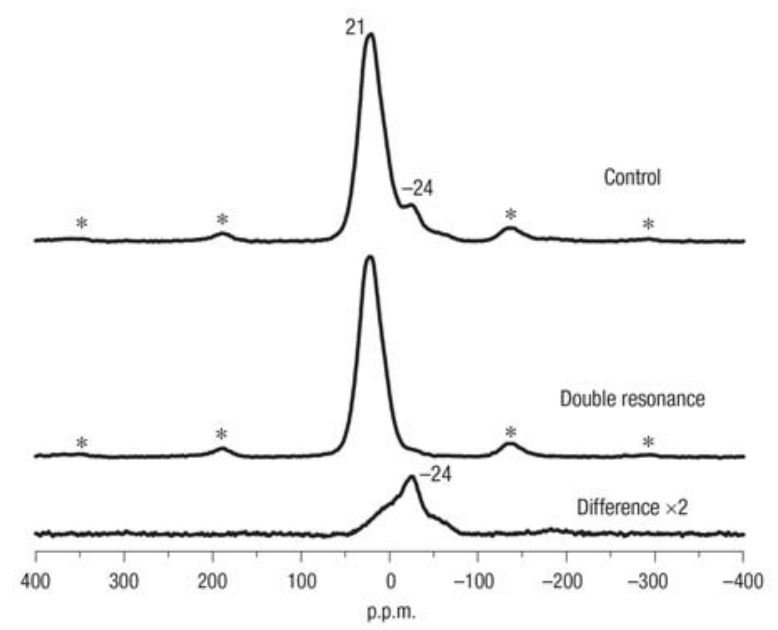

Fig. 3. ${ }^{17} \mathrm{O}^{-1} \mathrm{H}$ REDOR NMR spectra of ${ }^{17} \mathrm{O}$-enriched HY zeolite. The difference spectrum was obtained by subtracting the double resonance spectrum from the control spectrum [10]. troscopy, which provided insights into the active centers in acid-mediated zeolite catalysis [11,12].

The hydrothermal treatment of a zeolite usually results in the dealumination of the zeolite framework, which improves not only the thermal stability, but also the catalytic activity of the zeolite [13]. In zeolites, the 4-coordinate framework aluminum is associated with the Brönsted acid site (SiOHAl), while extra-framework aluminum (EFAL) species released from the zeolite framework during the dealumination acts as a Lewis acid site. Oxoaluminum cations, such as $\mathrm{AlO}^{+}, \mathrm{Al}(\mathrm{OH})_{2}{ }^{+}$and $\mathrm{AlOH}^{2+}$, and some neutral species such as $\mathrm{AlOOH}$ and $\mathrm{Al}(\mathrm{OH})_{3}$, were proposed as EFAL species although their detailed structures were not known [14]. Although there is no direct experimental evidence, a Brönsted/Lewis synergy was proposed to interpret the high catalytic activity of dealuminated zeolites. In order to better understand the synergy effect between Brönsted and Lewis acids, advanced 2D solid state NMR methods, such as ${ }^{1} \mathrm{H}$ [15] and ${ }^{27} \mathrm{Al}$ [16] double-quantum (DQ) magic angle spinning (MAS) NMR spectroscopy methods, were utilized to investigate the spatial proximity of the different acid sites in various zeolites.

The $2 \mathrm{D}^{1} \mathrm{H}$ DQ MAS NMR experiment is a robust technique for probing proton-proton proximities in materials. $2 \mathrm{D}{ }^{1} \mathrm{H}$ DQ MAS NMR was employed by Li et al. [17] for the first time to explore the spatial proximities of the various acid sites in dealuminated HY zeolites. Fig. 4 shows the 2D ${ }^{1} \mathrm{H}$ DQ MAS spectrum of dealuminated HY. Several types of correlation peaks were observed. The autocorrelation peaks at $\delta=(4.3$, 8.6) and $\delta=(5.0,10.0)$ suggested the spatial proximity of Brönsted acid sites in the supercage and sodalite cage, respectively. The autocorrelation peak at $\delta=(2.2,4.4)$ resulted from the formation of silanol groups during dealumination. Another autocorrelation peak at $\delta=(2.8,5.6)$ was due to EFAL species containing more than one hydroxyl groups. In addition, the off-diagonal peak pair at $\delta=(2.8,7.1)$ and $\delta=(4.3,7.1)$ represented the correlation between an extra-framework $\mathrm{AlOH}$ group and a Brönsted acidic proton in the supercage, suggesting the spatial proximity between the Brönsted and Lewis acid

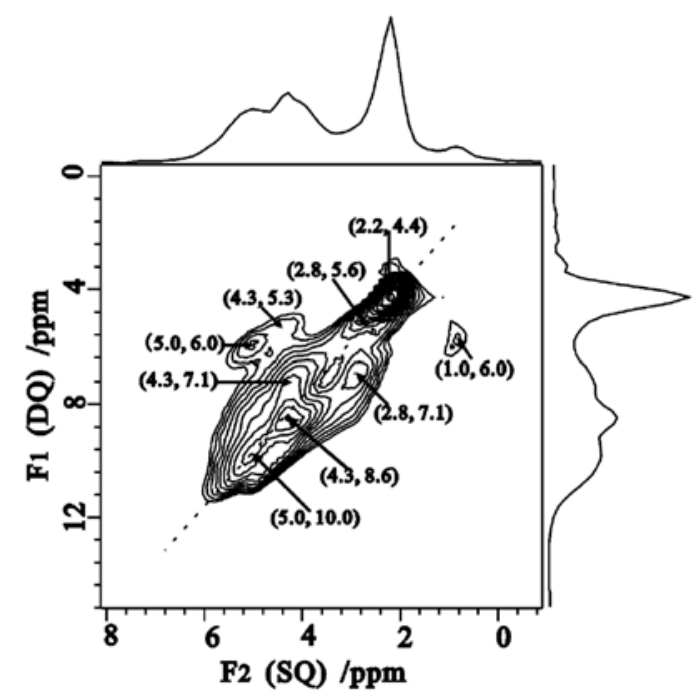

Fig. 4. $2 \mathrm{D}^{1} \mathrm{H}$ DQ MAS NMR spectra of dealuminated HY [17]. 
sites. Moreover, the results from ${ }^{13} \mathrm{C}$ NMR of adsorbed acetone and DFT calculation demonstrated that the spatial proximity of the Brönsted and Lewis acid sites resulted in a synergy effect that considerably enhanced the Brönsted acid strength of the dealuminated HY zeolite [17]. To measure the average ${ }^{1} \mathrm{H}-1 \mathrm{H}$ distance between various hydroxyl groups, additional 2D ${ }^{1} \mathrm{H} D Q$ MAS NMR experiments were performed with varying DQ recoupling time. The ${ }^{1} \mathrm{H}^{-1} \mathrm{H}$ distance between a Brönsted acidic proton and an extra-framework $\mathrm{AlOH}$ species in the supercage was determined to be $0.43 \mathrm{~nm}$ [18].

By using similar techniques, a comprehensive study was carried out to probe the spatial proximities between the different acid sites in $\mathrm{H}-\mathrm{Y}$ zeolite with different dealumination treatments (including calcination, steaming, and acid leaching) [18]. It was found that the Brönsted/Lewis acid synergy effect was always present in the samples prepared by the thermal and hydrothermal treatments, but absent in the samples prepared by the acid leaching treatment [18]. These findings provided insights into the roles of the Lewis acid and its synergy with the Brönsted acid in zeolite-mediated hydrocarbon reactions.

In addition to $2 \mathrm{D}{ }^{1} \mathrm{H}$ DQ MAS NMR, 2D ${ }^{27} \mathrm{Al}$ DQ MAS NMR can also be used to investigate the Brönsted and Lewis acid synergy in dealuminated zeolites. By utilizing a sensitivity-enhanced 2D ${ }^{27} \mathrm{Al}$ DQ MAS NMR technique [20], the spatial proximities of various $\mathrm{Al}$ species in dealuminated HY zeolites were demonstrated [19]. Fig. 5 shows the 2D ${ }^{27} \mathrm{Al}$ DQ MAS NMR spectra of the parent HY and calcined HY zeolites. For the parent HY, as shown in Fig. 5(a), the autocorrelation peak at $\delta=(61,122)$ indicated that the four-coordinate framework Al (FAL) species were in close proximity to one another. For the HY zeolite calcined at $500{ }^{\circ} \mathrm{C}$ (denoted as HY-500), the cross peak pair at $\delta=$ $(61,61)$ and $\delta=(0,61)$ resulted from the spatial proximity of the four-coordinated FAL and the six-coordinated EFAL (see
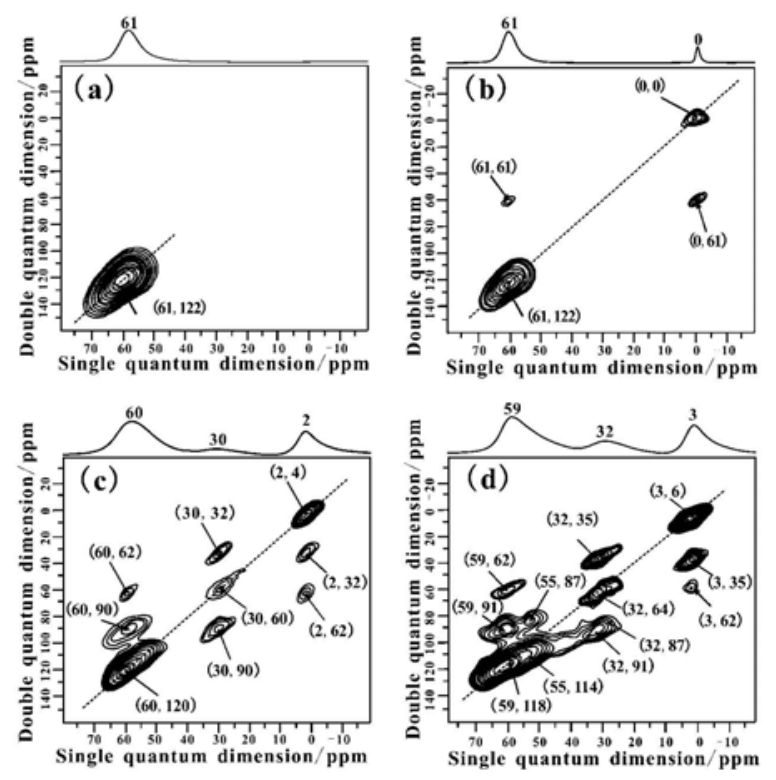

Fig. 5. 2D ${ }^{27} \mathrm{Al}$ DQ-MAS NMR spectra of (a) parent HY, (b) HY-500, (c) HY-600, and (d) HY-700 zeolites. 1D ${ }^{27} \mathrm{Al}$ MAS spectra are plotted on top of the 2D ${ }^{27} \mathrm{Al}$ DQ MAS spectra [19].
Fig. 5(b)), implying the existence of Brönsted and Lewis acid synergy in the dealuminated HY zeolite. For the HY-600 sample, three kinds of aluminum species including four-coordinated FAL, five-coordinated EFAL and six-coordinated EFAL were in close proximity (Fig. 5(c)). In the 2D ${ }^{27} \mathrm{Al}$ DQ MAS NMR spectrum of the HY-700 sample (Fig. $5(\mathrm{~d}))$, the correlation peak pair at $\delta=(55,87)$ and $\delta=(32,87)$ was ascribed to the spatial proximity between four-coordinated EFAL species and five-coordinated EFAL species. On the basis of the experimental observations, the detailed spatial correlations among the various aluminum species in hydrated HY zeolites after dealumination were clearly identified. In combination with DFT theoretical calculation, a new dealumination mechanism was proposed and three types of EFAL species in close proximity to the framework aluminum were identified in dealuminated HY zeolites [19]. The spatial proximities of the Brönsted and Lewis acid sites in highly siliceous zeolites, such as H-MOR, H-ZSM-5, and MCM-22 zeolites [21], were also investigated by $2 \mathrm{D}{ }^{1} \mathrm{H}$ and ${ }^{27} \mathrm{Al}$ DQ MAS NMR experiments. It was found that the Brönsted and Lewis acid synergy was present in these highly siliceous zeolites as well.

To measure the Brönsted acid density in a zeolite, Peng et al. proposed a new method of using diphenyldiphosphines, $\mathrm{Ph}_{2} \mathrm{P}\left(\mathrm{CH}_{2}\right)_{n} \mathrm{PPh}_{2}(n=1,3,6)$, which are molecules having two basic sites. 2D 31P-31P DQ MAS NMR experiments were employed to probe the ${ }^{31} \mathrm{P}-31 \mathrm{P}$ inter-nuclear distances [22]. Using this technique, the density and distribution of the Brönsted acid sites in HY and H-ZMS-5 zeolites with different $\mathrm{Si} / \mathrm{Al}$ ratios were investigated [23].

Dynamic nuclear polarisation (DNP) NMR makes it possible to transfer the large Boltzman polarization of the electron spin reservoir to the nuclear spin reservoir to provide a boost in NMR signal intensity by several orders of magnitude. This dramatically increases the signal intensity and data acquisition rate in NMR experiments [25]. The development of the DNP technique is very promising for probing surface functionality in functional materials. In DNP surface enhanced NMR spectroscopy (DNP SENS) [26], a porous or particulate sample is wetted with a radical solution. The large polarization of the unpaired electrons of the radicals is then transferred to the surrounding nuclear spin with a typical signal enhancement of between 10 and 100. Recently, the DNP SENS technique was used to characterize a ${ }^{119} \mathrm{Sn}$-Beta zeolite, in which a ${ }^{119} \mathrm{Sn}$ NMR signal enhancement $(\varepsilon)$ of 75 was gained using biradicals [27]. In combination with theoretical calculations, structural information on the active site in the Sn- $\beta$ zeolite was achieved [24].

Fig. 6 shows the ${ }^{119} \mathrm{Sn}$ DNP-SENS CP magic angle turning (CPMAT) spectra of $5 \mathrm{wt} \% \mathrm{Sn}-\beta$ zeolite [24]. The isotropic NMR spectrum was observed in the indirect dimension $\left(\mathrm{F}_{1}\right)$ and the normal anisotropic CP spectrum was observed in the direct dimension $\left(\mathrm{F}_{2}\right)$.The chemical shift tensor parameters $\left(\delta_{\text {iso, }}\right.$ and $k$ ) were extracted by fitting the sidebands. The signal S3 at $\delta=$ -614 was similar to that observed for bulk $\mathrm{SnO}_{2}$, which is consistent with the octahedral environment of $\mathrm{Sn}$ in $\mathrm{SnO}_{2}$. In addition, the other two signals at $\delta=-659$ (S2) and $\delta=-685$ (S1) were associated with a slightly different CSA parameter. The chemical shifts and the skewness $(k)$ close to 0 indicated a 


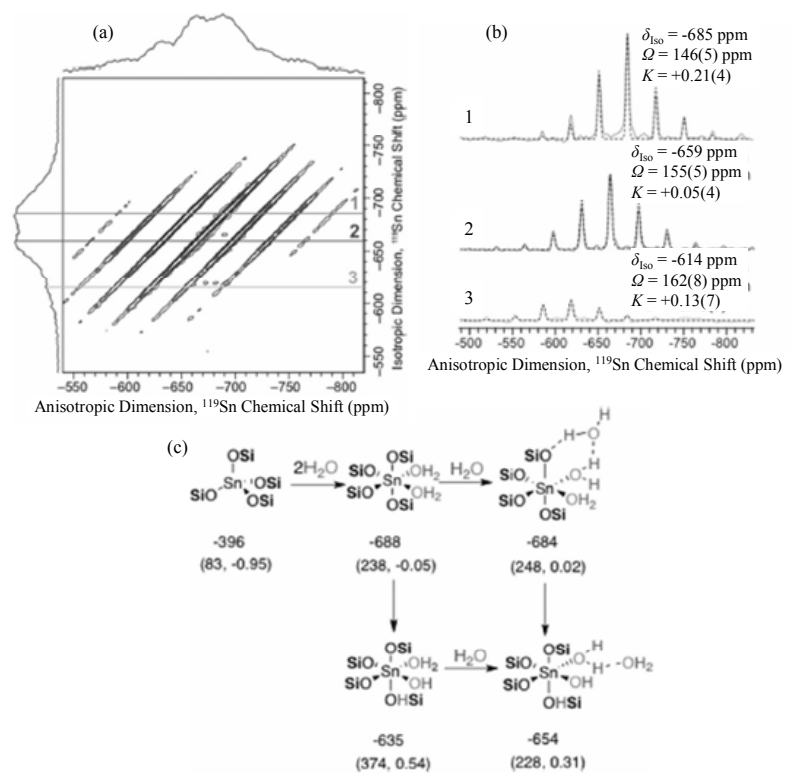

Fig. 6. (a) $105 \mathrm{~K}^{119} \mathrm{Sn}$ DNP-SENS CP magic angle turning (CPMAT) spectra of $5 \mathrm{wt} \%$ Sn- $\beta$ zeolite; (b) CS tensor parameters for the three different isotropic shifts are indicated; (c) Computed ${ }^{119} \mathrm{Sn}$ isotropic chemical shifts for each model [24].

slightly distorted octahedral Sn environment. The 2D CP/MAT experiment on $1 \mathrm{wt} \% \mathrm{Sn}-\beta$ showed two peaks at $\delta=-659$ and $\delta$ $=-685$ with similar CSA parameters to those observed with the $5 \mathrm{wt} \% \mathrm{Sn}-\beta$ sample, which is consistent with the presence of similar species and suggested that the increased loading did not change the nature of the Sn species but only their ratio [24]. To relate these observations to the local structure of the Sn environment, DFT calculations of cluster models were carried out to assign the observed NMR signals. These are shown in Fig. 6(c). By combining DNP-SENS spectroscopy and DFT calculations, it was shown that the active sites of Sn- $\beta$ zeolite was an octahedrally coordinated $\mathrm{Sn}^{\mathrm{IV}}$ involving tetrahedral Sn-sites and two water molecules [24].

\section{Solid state NMR studies of host-guest interaction in zeolites}

Host-guest interactions between guest molecules and the zeolite framework play essential roles in the shape selectivity in catalytic reactions. Thus, it is necessary to determine reliable structures of the zeolite-sorbate host-guest complexes. Fyfe et al. [28] applied ${ }^{1} \mathrm{H} /{ }^{29} \mathrm{Si}$ cross polarization (CP) MAS NMR experiments to determine the location of the guest molecules, adsorbed $p$-dichlorobenzene ( $p$-DCB), in highly siliceous zeolites. The ${ }^{1} \mathrm{H}-{ }^{29} \mathrm{Si}$ distances between the adsorbed molecule and zeolite framework can be extracted from the measured rates of the ${ }^{1} \mathrm{H} /{ }^{29} \mathrm{Si}$ cross polarization of the different Si sites as shown in Fig. 7. The location of the adsorbed molecule confined in the zeolite cage was calculated by fitting the experimental data as illustrated in Fig. 7 [28]. This method provided insight into the host-guest interaction model from the cross polarization from the adsorbate to the zeolite framework.

In addition, solid state NMR spectroscopy has also been em-

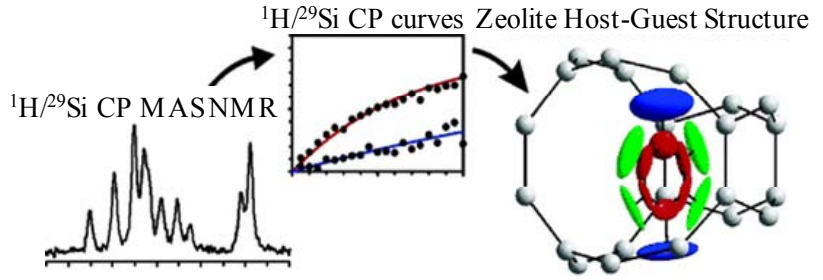

Fig. 7. Determination of zeolite host-guest structure complex from ${ }^{1} \mathrm{H}-{ }^{29} \mathrm{Si} \mathrm{CP} / \mathrm{MAS}$ NMR spectra [28].

ployed to investigate the host-guest interactions in various ordered mesoporous materials. 2D ${ }^{1} \mathrm{H}-{ }^{13} \mathrm{C}$ and ${ }^{1} \mathrm{H}-29$ Si HETCOR solid state NMR experiments were conducted to explore the structure-properties relationship of periodic mesoporous organosilicas hybrid p-phenylenesilica with crystalline order in the walls [29]. By using 2D ${ }^{1} \mathrm{H}-{ }^{13} \mathrm{C},{ }^{1} \mathrm{H}-27 \mathrm{Al}$ and ${ }^{1} \mathrm{H}-29$ Si HETCOR experiments, Chmelka and coworkers $[30,31]$ found that in the as-synthesized mesoporous MCM-41 material, tetrahedrally coordinated aluminum and silicon species were in close spatial proximity to the trimethylammonium head groups of the cationic surfactant species.

Aluminophosphate molecular sieves $\left(\mathrm{AlPO}_{4}-n\right)$ are usually prepared by hydrothermal synthesis and the crystalline molecular sieves are produced from the gel phase. In order to better understand the mechanism of molecular sieve crystallization, it is desirable to obtain detailed structural information for the surfactant in the evolution of the intermediate phases [32]. 2D ${ }^{1} \mathrm{H}^{-1} \mathrm{H}$ DQ MAS NMR was utilized to probe the proton-proton proximities of the various components of the surfactant $\mathrm{CTA}^{+}$to investigate the arrangement of the organic surfactant in the mesostructured aluminophosphate [33]. Fig. 8 shows the ${ }^{1} \mathrm{H} D Q$ MAS NMR spectra of aluminophosphate solids with different hydrothermal treatment time. Peaks $\mathrm{A}, \mathrm{B}$ and $\mathrm{C}$ represented alkyl chain $\mathrm{CH}_{3}$ protons, alkyl chain $\mathrm{CH}_{2}$ protons, and polar head $\mathrm{N}-\mathrm{CH}_{3} / \mathrm{N}-\mathrm{CH}_{2}-$ protons, respectively. In the ${ }^{1} \mathrm{H}$ DQ MAS NMR spectrum of the $1 \mathrm{~h}$ heated sample (Fig. 8(a)), three autocorrelation peaks (AA, BB, and $\mathrm{CC}$ ) and two pairs of off-diagonal peaks ( $\mathrm{AB}$ and $\mathrm{BC}$ ) were clearly observed, which resulted from hexagonal arrays of cylindrical micelles of $\mathrm{CTA}^{+}$cations. When the solid was heated for $3 \mathrm{~h}$ (Fig. 8(b)), a new off-diagonal peak AC appeared, indicating the inter-molecular spatial proximity of the nonpolar tail $\mathrm{CH}_{3}$ protons and the polar head $\mathrm{N}-\mathrm{CH}_{3} / \mathrm{N}-\mathrm{CH}_{2}-$ or $\mathrm{N}\left(\mathrm{CH}_{3}\right)_{4}{ }^{+}$protons in a planar structure, in which the surfactants were aggregated in the inter-digitated bilayer [33]. It was revealed that there may be a tilt angle for the long axis of the cetyl chains with respect to the aluminophosphate layers. In the spectrum of the $50 \mathrm{~h}$ heated sample (Fig. 8(c)), the off-diagonal peak AC was still observable, suggesting that the CTA+ bilayer also existed in a tail-to-head form. By utilizing ${ }^{1} \mathrm{H}-1 \mathrm{H}$ DQ MAS NMR spectroscopy, the surfactant was found to be arrayed inter-digitated in a bilayer with a tilt angle in the L1 phase while it was perpendicular in the L2 phase, which facilitated the phase transition during molecular sieve crystallization [33].

Solid state NMR spectroscopy is a robust technique for characterizing inorganic-organic hybrid mesostructured materials. It offers the possibility to directly investigate both bulk 

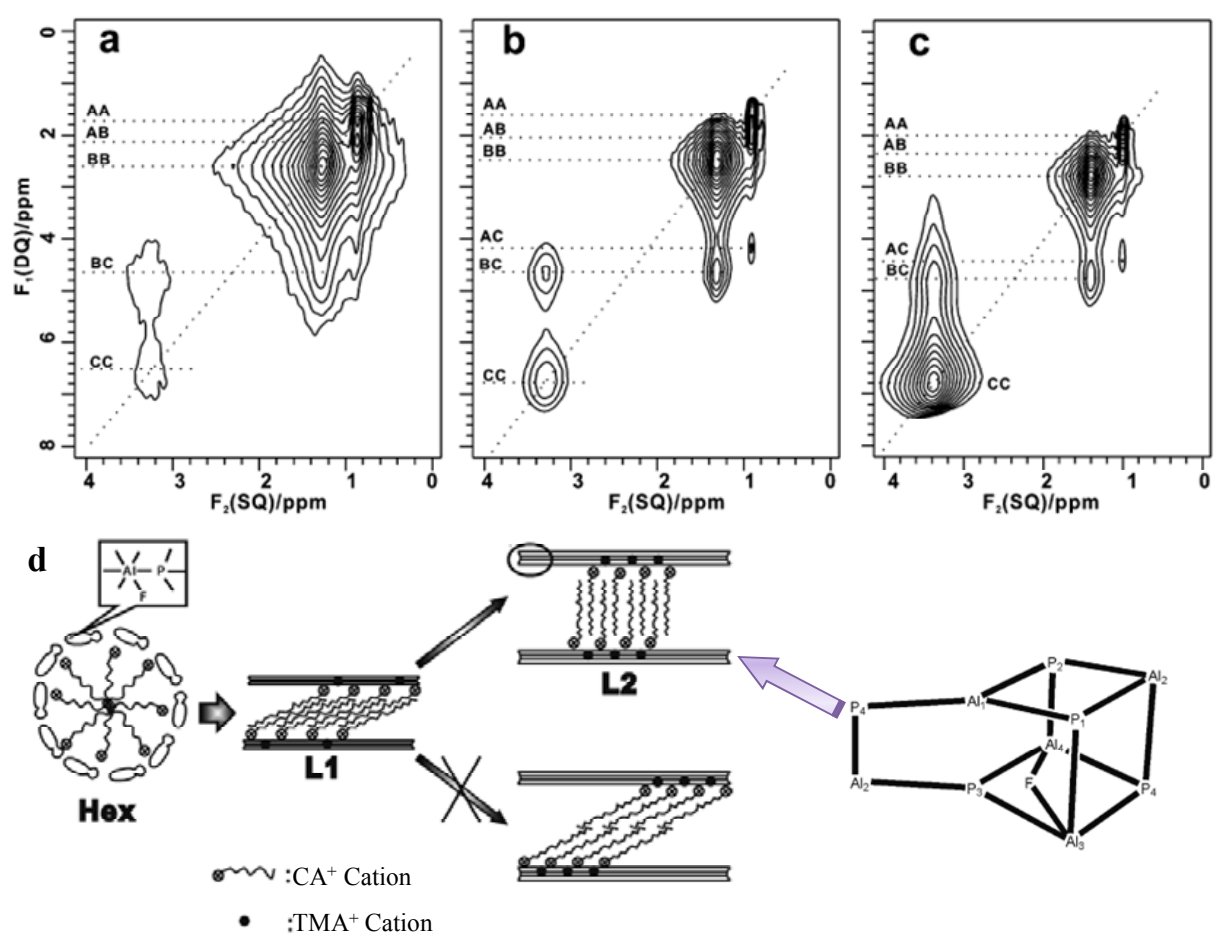

Fig. 8. 2D ${ }^{1} \mathrm{H}$ DQ MAS NMR spectra of aluminophosphate solids with different hydrothermal treatment time (a) $1 \mathrm{~h}$; (b) $3 \mathrm{~h}$; (c) $50 \mathrm{~h}$. The arrangement of the organic surfactant in the mesostructured aluminophosphate during crystallization process (d) [33].

(silica and/or alumina) and surface functionalities such as adsorbates, grafted molecules and organic fragments. However, the lower sensitivity of conventional solid state NMR methods prevents the precise exploration of host-guest interaction in functionalized mesostructured materials. Recently, Lesage and coworkers [34] utilized DNP-enhanced solid state NMR to investigate the host-guest interaction in the functionalization of siloxanes. Fig. 9 displays the ${ }^{13} \mathrm{C}$ CP MAS spectra of the organic-inorganic mesostructured materials in which the surface was functionalized with phenol. The spectrum was collected using the TOTAPOL radical as the polarization agent. Spectra were obtained with and without microwave irradiation. The signal enhancement factor was estimated to be greater than 56, which enabled the investigation of the surface substrate with its natural isotopic abundance. In addition, 2D surface-enhanced
1H-29Si DNP NMR spectra was further employed to identify and compare the bonding topology of the functional groups in materials obtained from a sol-gel process or by post-grafting reactions [35].

Host-guest interactions between the reactants and active sites play essential roles in adsorption, desorption and the catalytic reaction, which strongly influence the performance (activity and selectivity) of heterogeneous catalysts. The study of the host-guest interaction in zeolites is a straightforward and practical way for better understanding of the detailed mechanism of the catalytic reaction [36]. This information can be obtained from ${ }^{13} \mathrm{C}-\left\{{ }^{27} \mathrm{Al}\right\}$ symmetry-based rotational-echo saturation-pulse double-resonance (S-RESPDOR) experiments [37].

Fig. 10 shows the ${ }^{13} \mathrm{C}$ MAS spectra of $2-{ }^{13} \mathrm{C}$-acetone adsorbed on dealuminated $\mathrm{HY}$ zeolite acquired with and without ${ }^{13} \mathrm{C}-27 \mathrm{Al}$
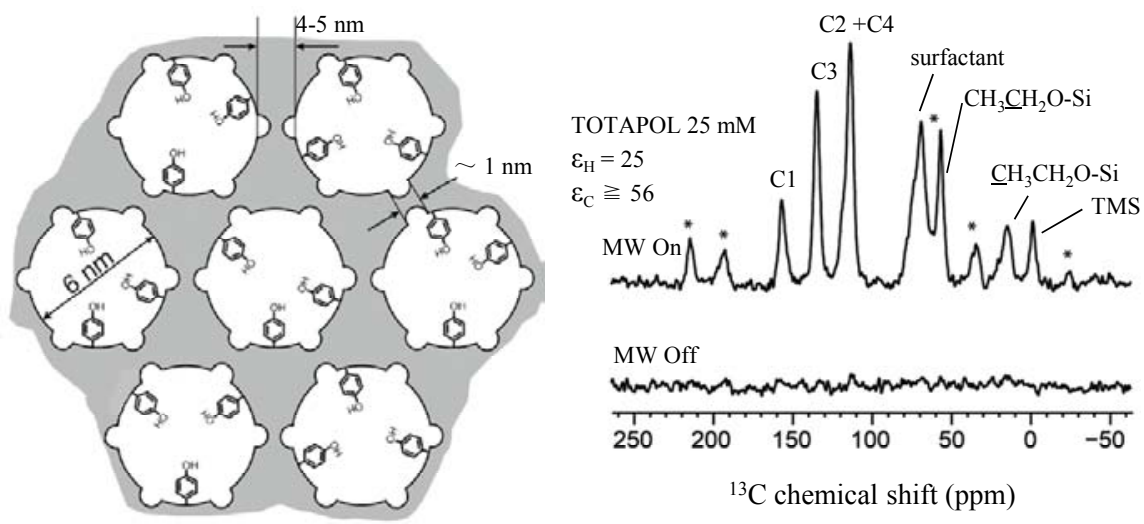

Fig. 9. ${ }^{13} \mathrm{C}$ CP MAS spectra of organic-inorganic mesostructured materials in which the surface was functionalized with phenol with and without MW irradiation at $263 \mathrm{GHz}$ to induce DNP [34]. 


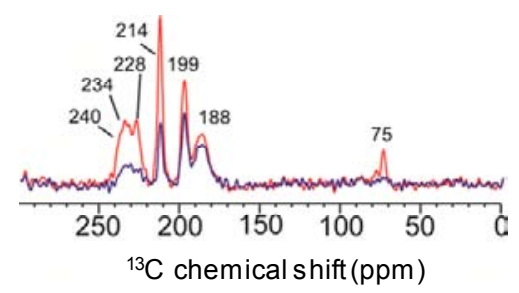

Fig. 10. ${ }^{13} \mathrm{C}$ MAS NMR spectra of $2-{ }^{13} \mathrm{C}$-acetone loaded on dealuminated HY zeolite. Blue and red lines represent the spectra observed with (S) and without $\left(\mathrm{S}_{0}\right){ }^{13} \mathrm{C}-\{27 \mathrm{Al}\}$-RESPDOR dipolar dephasing [38].

dipolar dephasing [38]. The interaction strength between the guest molecule and the acid site is shown by the ratio of $\mathrm{S}$ and So. It can be clearly observed that all the signals in the chemical shift range of $\delta=228-240$ were subject to a strong ${ }^{13} \mathrm{C}-27 \mathrm{Al}$ dipolar dephasing, which was ascribed to either a hydrogen bond interaction between the carbonyl oxygen of acetone and the Brönsted acid proton or to acetone directly bonded to the $\mathrm{Al}$ atom of the Lewis acid site. The smaller dephasing for the carbonyl group (214 ppm) [39] probably resulted from steric hindrance due to the larger size of diacetone alcohol/mesityl oxide. The vinyl groups of mesityl oxide associated with the signals in the $\delta=188-199$ range showed a smaller ${ }^{13} \mathrm{C}-27 \mathrm{Al}$ dipolar dephasing. The quaternary carbon at $\delta=75$ showed an intense ${ }^{13} \mathrm{C}-27 \mathrm{Al}$ dipolar dephasing, which was possibly due to the strong hydrogen bond interaction between the neighboring OH group in diacetone alcohol and the Brönsted acid site [38]. Therefore, the ${ }^{13} \mathrm{C}-{ }^{27} \mathrm{Al}$ solid state NMR technique provided experimental evidence of the interaction model between acetone and the Brönsted and Lewis acid sites in dealuminated HY zeolite. By utilizing the ${ }^{13} \mathrm{C}-\{27 \mathrm{Al}\} S$-RESPDOR experiment [40], the distances between adsorbed acetone and the reaction active centers were quantitatively determined [38]. In addition, the spatial interaction between adsorbed reactants with the different active centers (Brönsted and Lewis acids) was also clearly manifested from the $2 \mathrm{D}{ }^{27} \mathrm{Al}-\left\{{ }^{13} \mathrm{C}\right\} D$-HMQC experiment [41].

Several persistent reaction intermediates, such as 5- or 6- cyclic carbocations [42] and methoxy species [43], have been experimentally observed in zeolites using in situ MAS NMR techniques. Although the host-guest interactions between the reactants and intermediates and the acid sites can be easily demonstrated from DFT theoretical calculations [44], the experimental evidence to describe these kinds of interaction are still lacking. The combination of in situ MAS NMR and ${ }^{27} \mathrm{Al}-\left\{{ }^{13} \mathrm{C}\right\}$ S-RESPDOR experiments may give a new avenue for monitoring different reactions and elucidating the reaction mechanism in heterogeneous catalysis.

\section{Summary}

Solid state NMR is a well-established tool for the characterization of acid sites, determination of structure and investigation of host-guest interactions and catalytic reaction mechanisms over zeolites. In order to obtain a deeper insight into the structure-property relationship of zeolites, it is desirable to further develop solid state NMR techniques that enhance sensitivity and improve spectral resolution. This can be achieved by the design of versatile and robust NMR 1D or 2D pulse techniques and the hardware development of ultrahigh field NMR spectrometers. DNP is a very promising technique for enhancing NMR signals, and can be ultilized to detect previously undetectable NMR signals in zeolite systems. As external paramagntic centers must be introduced, the DNP technique has been only applied to study the surface property of mesoporous materials and the active sites in zeolites. It is still a challenge to study heterogeneously catalyzed reactions occuring in zeolites with the DNP technique. The fast acquisition methods and ultrahigh field spectroscopy involving quadrupolar nuclei facilitate the detection of active centers that have low sensitivity in zeolites.

\section{References}

[1] Hattori H. Chem Rev, 1995, 95: 537

[2] Massiot D, Messinger R J, Cadars S, Deschamps M, Montouillout V,

\section{Graphical Abstract}

Chin. J. Catal., 2015, 36: 789-796 doi: 10.1016/S1872-2067(14)60290-4

Recent advances in solid state NMR characterization of zeolites

Shenhui Li, Lei Zhou, Anmin Zheng, Feng Deng*

Wuhan Institute of Physics and Mathematics, Chinese Academy of Sciences

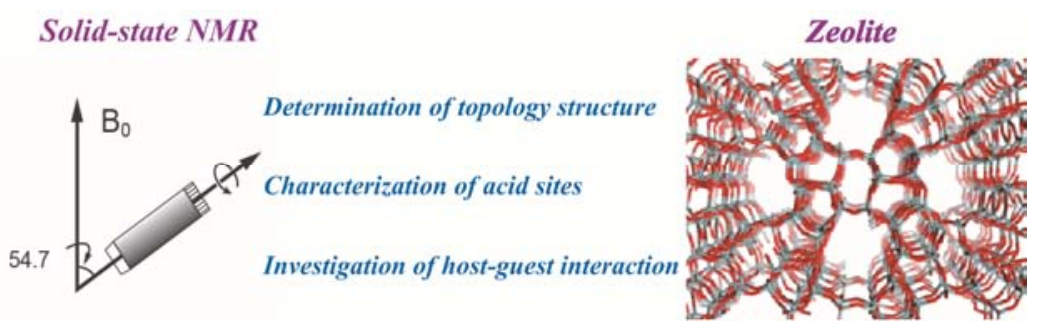

The recent research progress on advanced solid state NMR characterization of the structure, active sites (acid sites) and host-guest interaction in zeolites was reviewed. 
Pellerin N, Veron E, Allix M, Florian P, Fayon F. Acc Chem Res, 2013, 46: 1975

[3] Brouwer D H, Darton R J, Morris R E, Levitt M H. J Am Chem Soc, 2005, 127: 10365

[4] Brouwer D H, Kristiansen P E, Fyfe C A, Levitt M H. J Am Chem Soc, 2005, 127: 542

[5] Brouwer D H, Enright G D. J Am Chem Soc, 2008, 130: 3095

[6] Hammond K D, Dogan F, Tompsett G A, Agarwal V, Conner W C, Grey C P Jr, Auerbach S M. J Am Chem Soc, 2008, 130: 14912

[7] Cadars S, Brouwer D H, Chmelka B F. Phys Chem Chem Phys, 2009, 11: 1825

[8] Zheng A M, Huang X J, Wang Q, Zhang H L, Deng F, Liu S B. Chin J Catal (郑安民, 黄信炅, 王强, 张海禄, 邓风, 刘尚斌. 催化学报), 2013, 34: 436

[9] Zheng A M, Liu S B, Deng F. Solid State Nucl Magn Reson, 2013, 55-56: 12

[10] Peng L M, Liu Y, Kim N J, Readman J E, Grey C P. Nat Mater, 2005, 4: 216

[11] Peng L M, Huo H, Liu Y, Grey C P. J Am Chem Soc, 2007, 129: 335

[12] Huo H, Peng L M, Gan Z H, Grey C P. J Am Chem Soc, 2012, 134: 9708

[13] Sohn J R, DeCanio S J, Fritz P O, Lunsford J H. J Phys Chem, 1986, 90: 4847

[14] Shannon R D, Gardner K H, Staley R H, Bergeret G, Gallezot P, Auroux A. J Phys Chem, 1985, 89: 4778

[15] Feike M, Demco D E, Graf R, Gottwald J, Hafner S, Spiess H W. J Magn Reson A, 1996, 122: 214

[16] Mali G, Taulelle F. Chem Commun, 2004: 868

[17] Li S H, Zheng A M, Su Y C, Zhang H L, Chen L, Yang J, Ye C H, Deng F. J Am Chem Soc, 2007, 129: 11161

[18] Li S H, Huang S J, Shen W L, Zhang H L, Fang H J, Zheng A M, Liu S B, Deng F. J Phys Chem C, 2008, 112: 14486

[19] Yu Z W, Zheng A M, Wang Q Chen L, Xu J, Amoureux J P, Deng F. Angew Chem Int Ed, 2010, 49: 8657

[20] Wang Q, Hu B, Lafon O, Trebosc J, Deng F, Amoureux J P. J Magn Reson, 2009, 200: 251

[21] Yu Z W, Li S H, Wang Q, Zheng A M, Xu J, Chen L, Deng F. J Phys Chem C, 2011, 115: 22320

[22] Peng L M, Chupas P J, Grey C P. J Am Chem Soc, 2004, 126: 12254

[23] Peng L M, Grey C P. Micropor Mesopor Mater, 2008, 116: 277
[24] Wolf P, Valla M, Rossini A J, Comas-Vives A, Núñez-Zarur F, Malaman B, Lesage A, Emsley L, Copéret C, Hermans I. Angew Chem Int Ed, 2014, 53: 10179

[25] Ni Q Z, Daviso E, Can T V, Markhasin E, Jawla S K, Swager T M, Temkin R J, Herzfeld J, Griffin R G. Acc Chem Res, 2013, 46: 1933

[26] Rossini A J, Zagdoun A, Lelli M, Lesage A, Copéret C, Emsley L. Acc Chem Res, 2013, 46: 1942

[27] Gunther W R, Michaelis V K, Caporini M A, Griffin R G, Román-Leshkov Y.J Am Chem Soc, 2014, 136: 6219

[28] Fyfe C A, Brouwer D H. J Am Chem Soc, 2006, 128: 11860

[29] Comotti A, Bracco S, Valsesia P, Ferretti L, Sozzani P. J Am Chem Soc, 2007, 129: 8566

[30] Janicke M T, Landry C C, Christiansen S C, Kumar D, Stucky G D, Chmelka B F. J Am Chem Soc, 1998, 120: 6940

[31] Christiansen S C, Zhao D Y, Janicke M T, Landry C C, Stucky G D, Chmelka B F. J Am Chem Soc, 2001, 123: 4519

[32] Chen B H, Huang Y N.J Am Chem Soc, 2006, 128: 6437

[33] Shen W L, Li S H, Xu J, Zhang H L, Hu W, Zhou D, Zhang J N, Yu J H, Xu W J, Xu Y, Deng F. J Phys Chem C, 2010, 114: 7076

[34] Lesage A, Lelli M, Gajan D, Caporini M A, Vitzthum V, Miéville P, Alauzun J, Roussey A, Thieuleux C, Mehdi A, Bodenhausen G, Coperet C, Emsley L.J Am Chem Soc, 2010, 132: 15459

[35] Lelli M, Gajan D, Lesage A, Caporini M A, Vitzthum V, Miéville P, Héroguel F, Rascón F, Roussey A, Thieuleux C, Boualleg M, Veyre L, Bodenhausen G, Coperet C, Emsley L. J Am Chem Soc, 2011, 133: 2104

[36] Li S H, Deng F. Annu Rep NMR Spectrosc, 2013, 78: 1

[37] Gan Z H. Chem Commun, 2006: 4712

[38] Li S H, Pourpoint F, Trébosc J, Zhou L, Lafon O, Shen M, Zheng A M, Wang Q, Amoureux J P, Deng F.J Phys Chem Lett, 2014, 5: 3068

[39] Xu T, Munson E J, Haw J F. J Am Chem Soc, 1994, 116: 1962

[40] Pourpoint F, Trébosc J, Gauvin R M, Wang Q, Lafon O, Deng F, Amoureux J P. ChemPhysChem, 2012, 13: 3605

[41] Tricot G, Lafon 0, Trebosc J, Delevoye L, Mear F, Montagne L, Amoureux J P. Phys Chem Chem Phys, 2011, 13: 16786

[42] Haw J F, Song W G, Marcus D M, Nicholas J B. Acc Chem Res, 2003, 36: 317

[43] Wang W, Hunger M. Acc Chem Res, 2008, 41: 895

[44] Chu Y Y, Han B, Zheng A M, Deng F. J Phys Chem C, 2012, 116: 12687

\title{
固体核磁共振研究分子篮的新进展
}

\author{
李申慧, 周雷, 郑安民, 邓 风* \\ 中国科学院武汉物理与数学研究所，波谱与原子分子物理国家重点实验室，武汉磁共振中心，湖北武汉430071
}

摘要: 分子篮由于具有独特的孔道及可调控酸碱性等特征, 被作为离子交换剂、吸附剂及催化剂而广泛应用于石油化工的各种催 化过程中. 固体核磁共振是研究分子篮结构、酸性及主客体相互作用的强有力谱学手段之一. 简单概述了固体核磁共振研究分子 篮的最近进展.

关键词：固体核磁共振; 分子篮; 结构表征; 酸性位; 主客体相互作用

收稿日期: 2014-11-07. 接受日期: 2014-12-11. 出版日期: 2015-06-20.

*通讯联系人. 电话: (027)87198820; 传真: (027)97199291; 电子信箱: dengf@wipm.ac.cn

基金来源：国家自然科学基金(21210005, 21221064, 21373265).

本文的英文电子版由Elsevier出版社在ScienceDirect上出版(http://www.sciencedirect.com/science/journal/18722067). 